\title{
Capsaicin suppresses breast cancer cell viability by regulating the CDK8/PI3K/Akt/Wnt/B-catenin signaling pathway
}

\author{
DI WU* , HONGYAO JIA ${ }^{*}$, ZHIRU ZHANG and SIJIE LI \\ Department of Breast Surgery, The First Hospital of Jilin University, Changchun, Jilin 130021, P.R. China
}

Received May 6, 2020; Accepted September 4, 2020

DOI: $10.3892 / \mathrm{mmr} .2020 .11585$

\begin{abstract}
Breast cancer displays high morbidity and mortality. Despite exerting certain effects, traditional treatments cannot eliminate every cancer cell and may kill normal cells due to inaccurate targeting. However, as a traditional Chinese medicine, capsaicin, an active compound extracted from chili peppers, has displayed potent anticarcinogenic activities in vitro and in vivo, but the underlying mechanism is not completely understood. The pharmacological effects of capsaicin on tumors was evaluated in MDA MB 231 breast cancer cells. The MTT, cell scratch assay, cell cycle analysis, cell transfection, reverse transcription-quantitative PCR and western blotting were performed to investigate the potential antitumor mechanisms of capsaicin. In the present study, the potential anticancer mechanism underlying capsaicin in MDA-MB-231 cells in vitro was investigated. Capsaicin significantly inhibited MDA-MB-231 breast cancer cell viability and migration compared with the control group. The flow cytometry results indicated that capsaicin induced $G_{2} / M$ cell cycle arrest in MDA-MB-231 cells. In addition, capsaicin significantly reduced the expression of cyclin-dependent kinase 8 (CDK8) in breast cancer cells compared with the control group. Moreover, LV-CDK8 small interfering RNA-transduced MDA-MB-231 cells displayed lower CDK8 mRNA and protein expression levels compared with LV-negative control-shRNA-transduced cells. Furthermore, capsaicin significantly reduced the expression levels of phosphorylated (p)-PI3K, p-Akt, Wnt and $\beta$-catenin in vitro compared with the control group. Collectively, the results of the present study suggested that capsaicin inhibited breast cancer cell viability, induced $\mathrm{G}_{2} / \mathrm{M}$ cell cycle arrest, reduced
\end{abstract}

Correspondence to: Professor Sijie Li, Department of Breast Surgery, The First Hospital of Jilin University, 71 Xinmin Street, Changchun, Jilin 130021, P.R. China

E-mail: 1sj2019sci@163.com

*Contributed equally

Key words: capsaicin, breast cancer, cyclin-dependent kinase 8 , $\mathrm{G}_{2} / \mathrm{M}$ cell cycle arrest, PI3K/Akt, Wnt/ $\beta$-catenin
CDK8 expression levels, decreased the phosphorylation of $\mathrm{PI} 3 \mathrm{~K}$ and Akt and downregulated Wnt and $\beta$-catenin expression levels in MDA-MB-231 cells.

\section{Introduction}

Breast cancer is one of the most common malignancies in women worldwide (1). According to incomplete statistics, $\sim 1.7$ million new breast cancer cases are reported each year, accounting for $11.6 \%$ of all new cancer cases $(1,2)$. Based on this increasing rate, it has been estimated that the number of breast cancer cases and deaths worldwide will reach 2.64 million and 1.7 million in 2030, respectively (3). Although the diagnosis and treatment of breast cancer have markedly improved in recent years, a number of patients experience post-treatment recurrence and metastasis (4), and the mechanism underlying breast cancer is not completely understood. Therefore, identifying novel strategies to prevent the recurrence and metastasis of breast cancer, and to further improve the survival rate and quality of life of patients with breast cancer is important.

Cyclin-dependent kinases (CDKs), a member of the serine/threonine protein kinase family, can coordinate critical regulatory events during the cell cycle and transcription (5). Uncontrolled cell division is one of the hallmarks of cancer, and alterations in at least one $\mathrm{CDK}$ regulator or effector have been identified in almost all types of cancer (6). Moreover, inhibiting the cell cycle has been reported as a successful therapeutic strategy in oncology $(7,8)$. CDK8, as a member of the CDK family, serves an important role in gene transcription (9). Specifically, CDK8 has been reported to regulate the cell cycle and proliferation at the post-transcriptional level, and promote the development of various tumors, such as melanoma, acute myeloid leukemia (AML) and breast cancer $(10,11)$.

Previous studies have indicated that CDK8 impacts various signaling pathways, including the $\beta$-catenin (12), p53 (13) and Notch1 $(13,14)$ signaling pathways. A recent studies has revealed that CDK8 and the $\mathrm{Wnt} / \beta$-catenin signaling pathway serve key roles in breast cancer (15). Aberrant activation of the $\mathrm{Wnt} / \beta$-catenin signaling pathway causes $\beta$-catenin accumulation in the nucleus and can induce breast cancer (12). Firestein et al (12) demonstrated that CDK8 can increase the level of $\beta$-catenin in the cytoplasm, promote its translocation to the nucleus and binding to the TCF/LEF element, activate certain oncogenes, and promote the unrestricted proliferation of primary cells by unrestricted transcription and translation, 
which eventually leads to tumorigenesis. Additionally, it has been reported that CDK8 gene knockout can inhibit the activation of $\beta$-catenin and its downstream signaling, thereby inhibiting tumor cell proliferation, invasion and metastasis (16). Collectively, the aforementioned studies indicated that CDK8 may serve as a potential therapeutic target for breast cancer.

Capsaicin, an active ingredient extracted from chili pepper, has been reported to display multiple pharmacological effects, including analgesic and anticancer effects (17). Capsaicin can be absorbed into the blood circulation via the digestive system and is eventually eliminated by the liver (18). Studies have demonstrated that capsaicin, if formed into liposomes or encapsulated in nanocapsules, can be accurately delivered to tumor tissue $(18,19)$. Additionally, it has been reported that capsaicin can inhibit B16-F10 melanoma cell migration by inhibiting the PI3K/Akt/Rac family small GTPase 1 (Rac1) signaling pathway (20). Although the aforementioned studies demonstrated the anticancer effects of capsaicin, the studies did not clearly explain the underlying mechanisms. Therefore, the present study investigated the antitumor effect of capsaicin on MDA-MB-231 breast cancer cells and explored the potential anticancer mechanism underlying capsaicin via inhibition of the CDK8/PI3K/Akt/Wnt/ $\beta$-catenin signaling pathway.

\section{Materials and methods}

Cell culture. The MDA-MB-231 breast cancer cell line and the MCF10A healthy breast cell line were purchased from the American Type Culture Collection. Cells were cultured in L-15 medium (Nanjing KeyGen Biotech Co., Ltd.) supplemented with 10\% FBS (Gibco; Thermo Fisher Scientific, Inc.), $100 \mathrm{U} / \mathrm{ml}$ penicillin and $100 \mathrm{U} / \mathrm{ml}$ streptomycin (Nanjing KeyGen Biotech Co., Ltd.) in humidified $5 \% \mathrm{CO}_{2}$ at $37^{\circ} \mathrm{C}$.

Drugs and reagents. The primary antibodies targeted against CDK8 (cat. no. 17395); p-PI3K (cat. no. 17366), PI3K (cat. no. 4255), p-Akt (cat. no. 4060), Akt (cat. no. 4685), $\beta$-catenin (cat.no. 8480) and Wnt (cat. no. 2721) were purchased from Cell Signaling Technology, Inc. The primary antibody targeted against GAPDH (cat. no. 14-9523-37) was purchased from Sigma-Aldrich (Merck KGaA). Capsaicin was purchased from Sigma-Aldrich (Merck KGaA), diluted in DMSO at $100 \mathrm{mM}$ and stored at $-20^{\circ} \mathrm{C}$. LY294002 and Senexin A were purchased from MedChemExpress. FBS were purchased from Gibco (Thermo Fisher Scientific, Inc.). Cell Cycle and Apoptosis Analysis Kit (cat. no. C1052) was purchased from Beyotime Institute of Biotechnology. All other chemicals were purchased from Sigma-Aldrich (Merck KGaA).

Cell viability assay. Cell viability was assessed by performing MTT assays. Briefly, MDA-MB-231 cells were seeded (1x10 4 cells/well) into a 96-well plate and cultured for $24 \mathrm{~h}$. Cells were then incubated with different concentrations of capsaicin $(0,10,50,100$ or $200 \mu \mathrm{M})$ for $48 \mathrm{~h}$ at $37^{\circ} \mathrm{C}$ with $5 \% \mathrm{CO}_{2}$. Subsequently, $20 \mu \mathrm{l}$ MTT solution $(5 \mathrm{mg} / \mathrm{ml})$ was added to each well for $4 \mathrm{~h}$ at $37^{\circ} \mathrm{C}$ with $5 \% \mathrm{CO}_{2}$. The supernatant was removed and $100 \mu \mathrm{l}$ DMSO was added to each well to dissolve the formazan crystal. Absorbance was measured at a wavelength of $450 \mathrm{~nm}$ using an ELISA microplate reader (PerkinElmer, Inc.). Cell viability is presented as the mean $\pm \mathrm{SD}$ of three independent experiments.

Wound healing assay. Cells were seeded $\left(1 \times 10^{6}\right.$ cells/well) into a 6-well plate and cultured to 40-50\% confluence. Subsequently, cells were incubated with different concentrations of capsaicin $(0,10,50,100$ and $200 \mu \mathrm{M})$ for $24 \mathrm{~h}$ at $37^{\circ} \mathrm{C}$ with $5 \% \mathrm{CO}_{2}$ until the cell monolayer reached $100 \%$ confluence. The medium was then replaced with serum-free medium. The cell monolayer was scratched with a $10-\mu 1$ pipette tip and washed three times with PBS to remove cell debris. The width of the wound was observed at 0 and $48 \mathrm{~h}$ using an inverted light microscope and calculated using ImageJ software (version 1.8.0; National Institutes of Health). The rate of cell migration was calculated according to the following formula: Experimental group migration distance/control group migration distance. The wound healing assay was performed in triplicate.

Cell cycle analysis. Cells in the logarithmic growth phase were seeded $\left(2 \times 10^{5}\right.$ cells/well) into a 6 -well plate and incubated at $37^{\circ} \mathrm{C}$ for $24 \mathrm{~h}$. The medium was replaced with serum-free medium. Cells were incubated with or without capsaicin $(0,10,50,100$ and $200 \mu \mathrm{M})$ for $48 \mathrm{~h}$ at $37^{\circ} \mathrm{C}$. Subsequently, cells were collected, washed with pre-cooled PBS and fixed with $70 \%$ ethanol overnight at $4^{\circ} \mathrm{C}$. After washing with PBS, cells were incubated with $10 \mu \mathrm{g} / \mathrm{ml} \mathrm{RNase}$ at $37^{\circ} \mathrm{C}$ for $30 \mathrm{~min}$. Subsequently, cells were incubated with $2 \mathrm{mg} / \mathrm{ml}$ propidium iodide (PI; final concentration, $10 \mu \mathrm{g} / \mathrm{ml}$ ) for $30 \mathrm{~min}$ at room temperature in the dark. Cell cycle distribution was analyzed using a FACSCalibur analyzer (BD Biosciences). Flow cytometry was performed in triplicate.

Cell transduction. MDA-MB-231 cells were seeded $\left(1 \times 10^{6}\right.$ cells/well $)$ into a 6 -well plate for $24 \mathrm{~h}$ at $37^{\circ} \mathrm{C}$. Lentiviral vectors [LVs; LV-CDK8-short hairpin (sh)RNA or LV-negative control (NC)-shRNA] (empty vector) were purchased from OBiO Technology (Shanghai) Corp., Ltd. Cells were transduced with $3.0 \times 10^{10} \mathrm{PFU} / \mathrm{ml}$ of LV-CDK8-shRNA or LV-NC-shRNA using Lipofectamine ${ }^{\circledR} 2000$ (Invitrogen; Thermo Fisher Scientific, Inc.) according to the manufacturer's protocol. At $48 \mathrm{~h}$ post-infection, cells were used for subsequent experiments.

Western blotting. Cells were seeded $\left(1 \times 10^{6}\right.$ cells/well $)$ into the 6-well plate and treated with or without capsaicin $(10,50$, 100 and $200 \mu \mathrm{M}$ ) for $24 \mathrm{~h}$ at $37^{\circ} \mathrm{C}$. Subsequently, cells were collected and total protein was extracted using RIPA lysis buffer (Thermo Fisher Scientific, Inc.). Total protein was quantified using a BCA Protein assay (Thermo Fisher Scientific, Inc.). A total of $40 \mu \mathrm{g}$ of proteins was loaded and separated by $10 \%$ SDS-PAGE and electrophoretically transferred onto polyvinylidene fluoride membranes (EMD Millipore). The membranes were blocked with $5 \%$ bovine serum albumin for $1 \mathrm{~h}$ at room temperature, probed with with primary antibodies targeted against: CDK8 (1:1,000), phosphorylated (p)-PI3K $(1: 1,000)$, PI3K (1:1,000), p-Akt $(1: 1,000)$, Akt $(1: 1,000)$, Wnt $(1: 1,000), \beta$-catenin $(1: 1,000)$ and GAPDH $(1: 8,000)$ overnight at $4^{\circ} \mathrm{C}$ and then incubated with horseradish peroxide-conjugated secondary antibodies [goat anti-rabbit $\operatorname{IgG}(\mathrm{H}+\mathrm{L})$; cat. no. 31460 or goat anti-mouse $\operatorname{IgG}(\mathrm{H}+\mathrm{L})$; cat. no. 31430; 
1:5,000; Chemicon International; Thermo Fisher Scientific, Inc.] for $2 \mathrm{~h}$ at room temperature. Protein bands were visualized using enhanced chemiluminescence reagents (PerkinElmer, Inc.) and the Gel Doc ${ }^{\mathrm{TM}} \mathrm{XR}, 170-8170$ Molecular Imager. Protein expression levels were semi-quantified using Quantity One software (version 4.6.5; Bio-Rad Laboratories, Inc.) with GAPDH as the loading control.

Reverse transcription-quantitative PCR (RT-qPCR). Total RNA was extracted from cells using TRIzol ${ }^{\circledR}$ reagent (Invitrogen; Thermo Fisher Scientific, Inc.) according to the manufacturer's protocol. Total RNA was reverse transcribed into cDNA using the All-in-One ${ }^{\mathrm{TM}}$ miRNA Q-PCR Detection kit (GeneCopoeia, Inc.). The temperature protocol of the reverse transcription step was as follows: $30^{\circ} \mathrm{C}$ for $10 \mathrm{~min}, 42^{\circ} \mathrm{C}$ for $30 \mathrm{~min}, 99^{\circ} \mathrm{C}$ for $5 \mathrm{~min}$ and $4^{\circ} \mathrm{C}$ for $5 \mathrm{~min}$ ). Subsequently, qPCR was performed using SYBR-Green Master Mix (Applied Biosystems; Thermo Fisher Scientific, Inc.) and a 7500 Fast Real-Time PCR system (Applied Biosystems; Thermo Fisher Scientific, Inc.). The following thermocycling conditions were used for qPCR: $95^{\circ} \mathrm{C}$ for $10 \mathrm{~min}$; followed by 40 cycles at $95^{\circ} \mathrm{C}$ for $10 \mathrm{sec}, 57^{\circ} \mathrm{C}$ for $20 \mathrm{sec}$ and $72^{\circ} \mathrm{C}$ for $15 \mathrm{sec}$. The following primers were used for qPCR: CDK8 forward, 5'-TCACCTTTG AAGCCTTTAGC-3' and reverse, 5'-CTGATGTAGGAAGTG GGTCT-3'; and GAPDH forward, 5'-CGGAGTCAACGGATT TGGTCGTAT-3' and reverse, 5'-AGCCTTCTCCATGGTGGT GAAGAC-3'. mRNA expression levels were quantified using the $2^{-\Delta \Delta C q}$ method (21) and normalized to the internal reference gene GAPDH. RT-qPCR was performed in triplicate.

Statistical analysis. Statistical analyses were performed using GraphPad Instat software (version 7.0; GraphPad Software, Inc.). Comparisons among multiple groups were analyzed using one-way ANOVA followed by Tukey's post hoc test. Data are presented as the mean \pm SD of the three independent experiments. $\mathrm{P}<0.05$ was considered to indicate a statistically significant difference.

\section{Results}

CDK8 $\mathrm{mRNA}$ and protein expression levels are significantly increased in MDA-MB-231 breast cancer cells. Previous studies have demonstrated that CDK8 serves a key role in increasing $\beta$-catenin expression levels and promoting cell proliferation in various types of cancer, such as prostate (22) and colorectal (23) cancer. In the present study, the mRNA and protein expression levels of CDK8 were measured in MDA-MB-231 breast cancer cells. The results suggested that CDK8 protein expression levels were significantly increased in MDA-MB-231 cells compared with MCF10A healthy breast cells (Fig. 1A). CDK8 mRNA expression levels were also significantly higher in MDA-MB-231 breast cancer cells compared with MCF10A healthy breast cells (Fig. 1B). These results suggested that CDK8 was upregulated in MDA-MB-231 breast cancer cells.

CDK8 enhances MDA-MB-231 breast cancer cell viability and migration. Previous studies have indicated that CDK8 functions as a transcriptional regulator and serves an important role in the development of melanoma, AML, prostate cancer
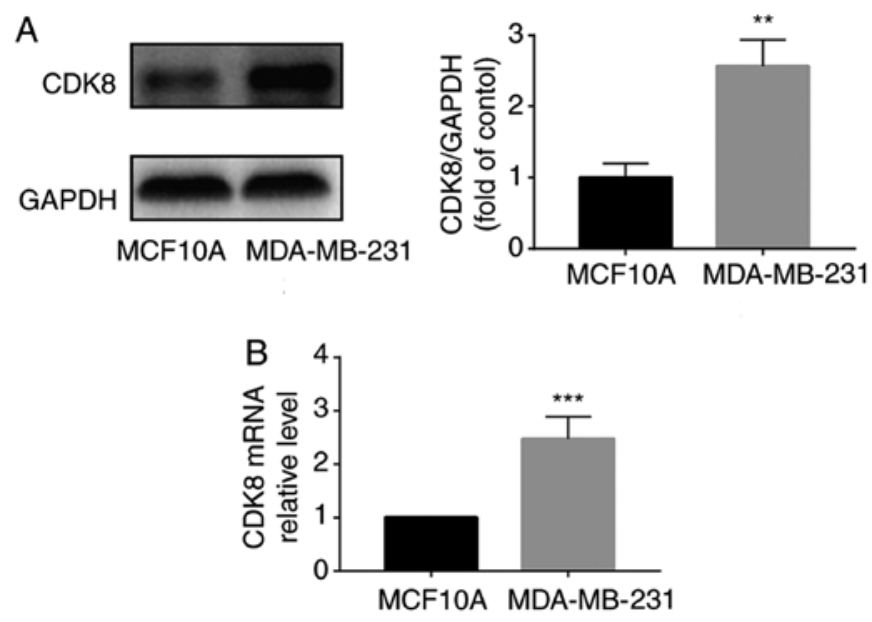

Figure 1. CDK8 mRNA and protein expression levels are significantly increased in MDA-MB-231 breast cancer cells. CDK8 (A) protein and (B) mRNA expression levels in MDA-MB-231 and MCF10A cells were detected by western blotting and reverse transcription-quantitative PCR, respectively. ${ }^{* *} \mathrm{P}<0.01$ and ${ }^{* * *} \mathrm{P}<0.001$ vs. MCF10A (one-way ANOVA). CDK8, cyclin-dependent kinase 8 .

and breast cancer $(11,24)$. The aforementioned results indicated that CDK8 was significantly upregulated in MDA-MB-231 cells; therefore, whether breast cancer cell viability was dependent on CDK8 was investigated. MDA-MB-231 cells were infected with LV-CDK8-shRNA and the control group was infected with LV-NC-shRNA. Subsequently, MTT and wound healing assays were performed to examine cell viability and migration in vitro, respectively. The western blotting and RT-qPCR results indicated that CDK8 expression was significantly decreased by LV-CDK8-shRNA compared with LV-NC-shRNA (Fig. 2A-C). Moreover, MDA-MB-231 cell viability (Fig. 2D) and migration (Fig. 2E and F) in the LV-CDK8-shRNA group were significantly lower compared with those in the LV-NC-shRNA group. The results indicated that MDA-MB-231 breast cancer cell viability and migration were dependent on CDK8.

Capsaicin inhibits breast cancer cell viability by reducing $C D K 8$. The MTT assay was performed to assess the antitumor effects of capsaicin in MDA-MB-231 breast cancer cells. The results indicated that low concentrations of capsaicin $(10,50$ and $100 \mu \mathrm{M})$ did not significantly alter cell viability, whereas $200 \mu \mathrm{M}$ capsaicin significantly reduced MDA-MB-231 breast cancer cell viability compared with the $0 \mu \mathrm{M}$ capsaicin group (Fig. 3A). The effects of capsaicin on MDA-MB-231 breast cancer cell migration were assessed. Capsaicin $(>10 \mu \mathrm{M})$ significantly inhibited MDA-MB-231 cell migration in vitro compared with the $0 \mu \mathrm{M}$ capsaicin group (Fig. 3B and C). Moreover, capsaicin significantly decreased the expression of CDK8 in MDA-MB-231 cells compared with the $0 \mu \mathrm{M}$ capsaicin group (Fig. 3D and E). Collectively, the results suggested that capsaicin had a potent inhibitory effect on MDA-MB-231 breast cancer cells.

Capsaicin induces $G_{2} / M$ cell cycle arrest in MDA-MB-231 breast cancer cells. To explore the potential anticancer mechanisms underlying capsaicin, capsaicin-induced alterations 
A

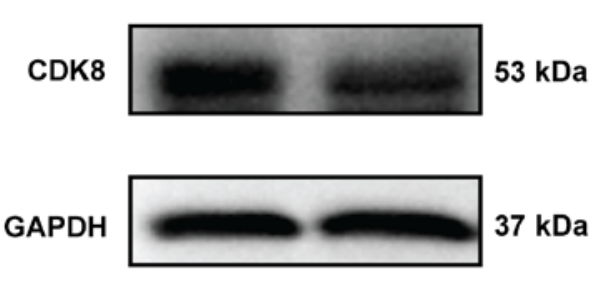

LV-NC-ShRNA LV-CDK8-ShRNA
B

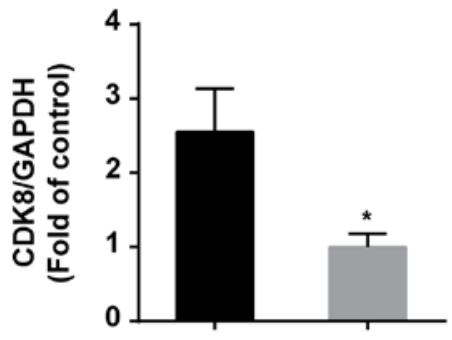

LV-NC-shRNA LV-CDK8-shRNA

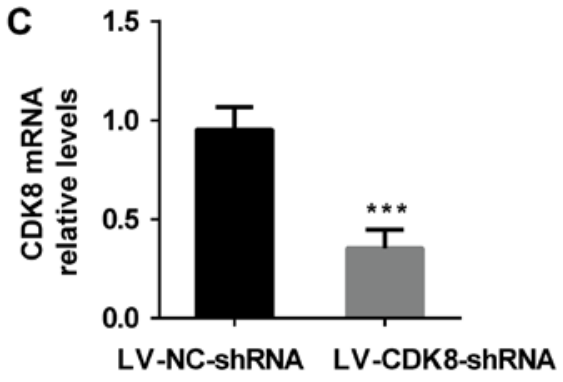

E

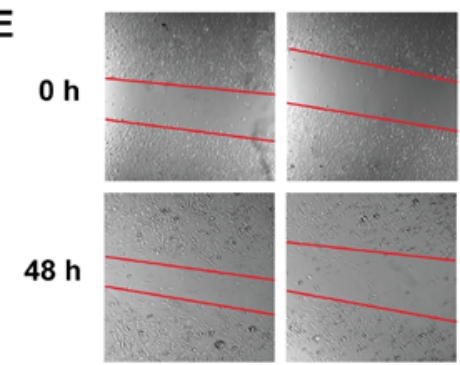

LV-NC-shRNA LV-CDK8-shRNA

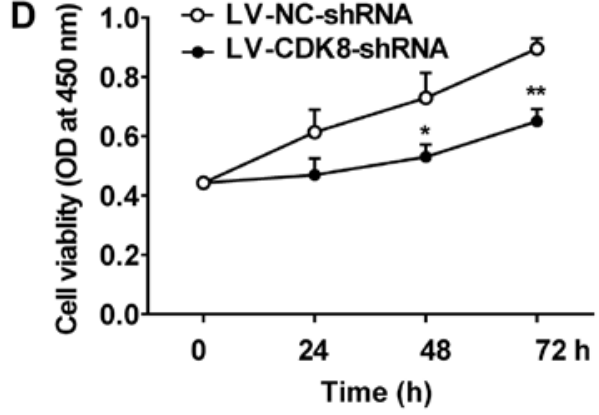

$\mathbf{F}$

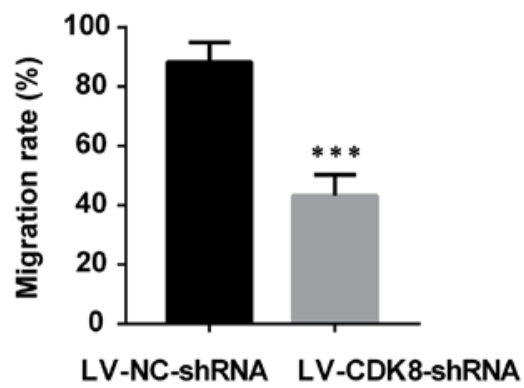

Figure 2. CDK8 enhances MDA-MB-231 breast cancer cell viability and migration. The infection efficiency of CDK8 knockdown was (A) determined by western blotting and (B) semi-quantified. (C) Infection efficiency of CDK8 knockdown was further assessed via reverse transcription-quantitative PCR (D) Effect of CDK8 knockdown on cell viability, as determined by MTT assay. The effect of CDK8 knockdown on cell migration was (E) assessed by performing a wound healing assay (magnification, $\mathrm{x} 400$ ) and $(\mathrm{F})$ the rate of migration was quantified. ${ }^{*} \mathrm{P}<0.05,{ }^{* *} \mathrm{P}<0.01$ and ${ }^{* * * *} \mathrm{P}<0.001 \mathrm{vs}$. LV-NC-shRNA (one-way ANOVA). CDK8, cyclin-dependent kinase 8; LV, lentiviral vector; NC, negative control; shRNA, short hairpin RNA; OD, optical density.

in the cell cycle distribution were assessed. MDA-MB-231 breast cancer cells were treated with or without capsaicin for $48 \mathrm{~h}$, and the cell cycle distribution was evaluated via flow cytometry. The results demonstrated that capsaicin induced cell cycle arrest at the $\mathrm{G}_{2} / \mathrm{M}$ phase (Fig. 4). The proportion of MDA-MB-231 cells at the $\mathrm{G}_{2} / \mathrm{M}$ phase increased from $11.46 \%$ in the $0 \mu \mathrm{M}$ capsaicin group to $16.74,18.23,21.58$ and $25.63 \%$ in the $10,50,100$ and $200 \mu \mathrm{M}$ capsaicin groups, respectively (Fig. 4). The results indicated that capsaicin could induce $\mathrm{G}_{2} / \mathrm{M}$ phase cell cycle arrest in MDA-MB-231 breast cancer cells.

Capsaicin inhibits breast cancer cell viability by downregulating the CDK8/PI3K/Akt signaling pathway. A previous study demonstrated the potent inhibitory effect of capsaicin on B16-F10 malignant melanoma cells and its potential relation to the PI3K/Akt/Racl signaling pathway (20). To assess the association between the antimigratory effects of capsaicin and the PI3K/Akt signaling pathway, the expression levels of the proteins involved in the signaling pathway were measured via western blotting. The results suggested that $>10 \mu \mathrm{M}$ capsaicin significantly reduced the expression levels of p-PI3K and p-Akt in MDA-MB-231 breast cancer cells compared with the control group (Fig. 5A-C). Furthermore, a specific inhibitor of PI3K (LY294002; $25 \mu \mathrm{M}$ ) was used to study the antimigratory effects of capsaicin. Pretreatment with LY294002 for $24 \mathrm{~h}$ significantly decreased the expression levels of p-PI3K and p-Akt in vitro compared with the control group (Fig. 5A-C). CDK8 inhibitor (Senexin A; $2.5 \mu \mathrm{M}$ ) also significantly reduced the expression levels of p-PI3K and p-Akt in vitro compared with the control group (Fig. 5A-C). Moreover, pretreatment with Senexin A also significantly inhibited MDA-MB-231 breast cancer cell viability and migration in vitro compared with the control group (Fig. 5D-F). The results indicated that the inhibitory effect of capsaicin on breast cancer cell viability was associated with suppressing the CDK8/PI3K/Akt signaling pathway.

Capsaicin significantly inhibits Wnt/ $\beta$-catenin signaling in MDA-MB-231 breast cancer cells. Previous studies have indicated that the canonical Wnt signaling pathway 

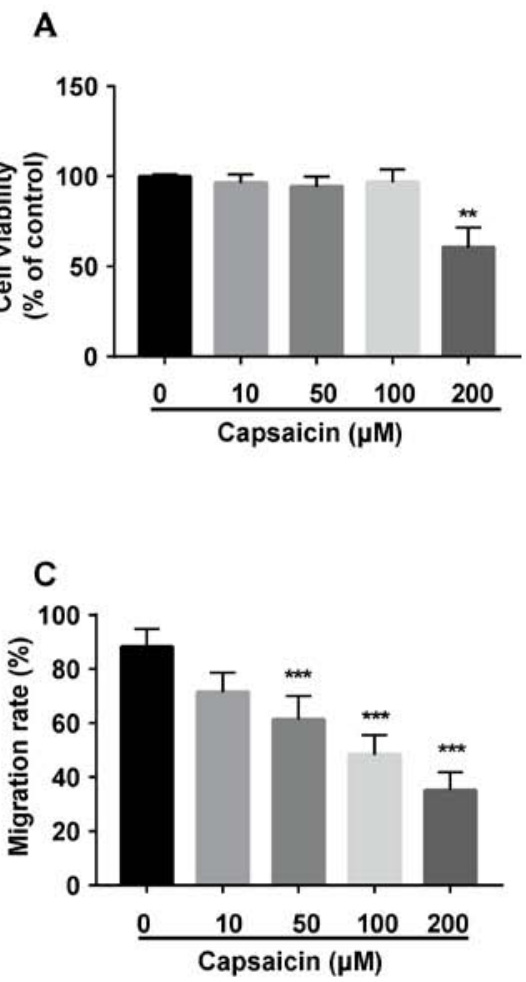

B

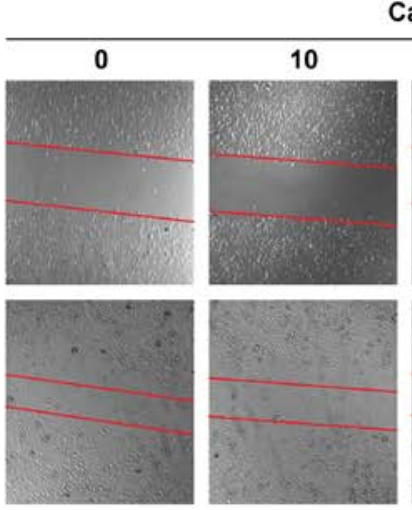

D

CDK8

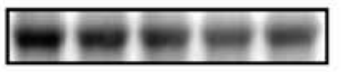

GAPDH

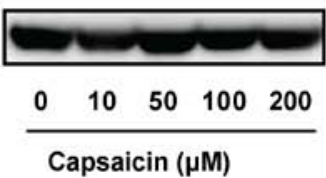

Capsaicin $(\mu \mathrm{M})$

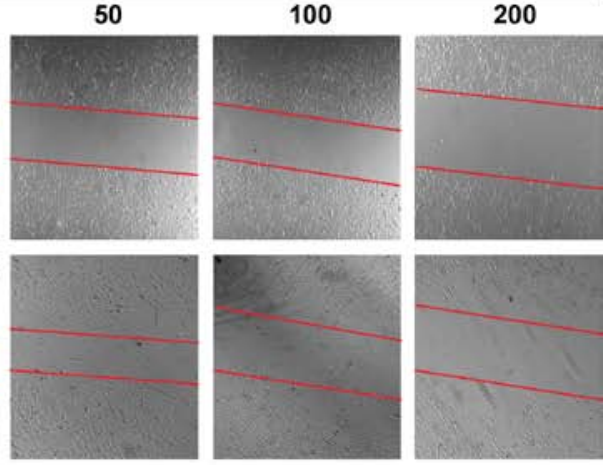

E

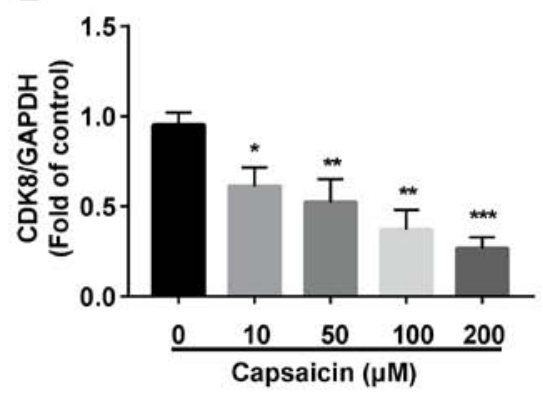

Figure 3. Capsaicin inhibits breast cancer cell viability by downregulating CDK8. (A) Effect of capsaicin on cell viability, as determined by MTT assay. The effect of capsaicin on cell migration was (B) determined by performing a wound healing assay (magnification, $\mathrm{x} 400)$ and (C) rate of migration was quantified. CDK8 protein expression levels were (D) determined via western blotting and (E) semi-quantified ( $\mathrm{n}=3)$. $\mathrm{P}<0.05,{ }^{* *} \mathrm{P}<0.01$ and ${ }^{* * * *} \mathrm{P}<0.001$ vs. $0 \mu \mathrm{M}$ capsaicin (one-way ANOVA). CDK8, cyclin-dependent kinase 8.

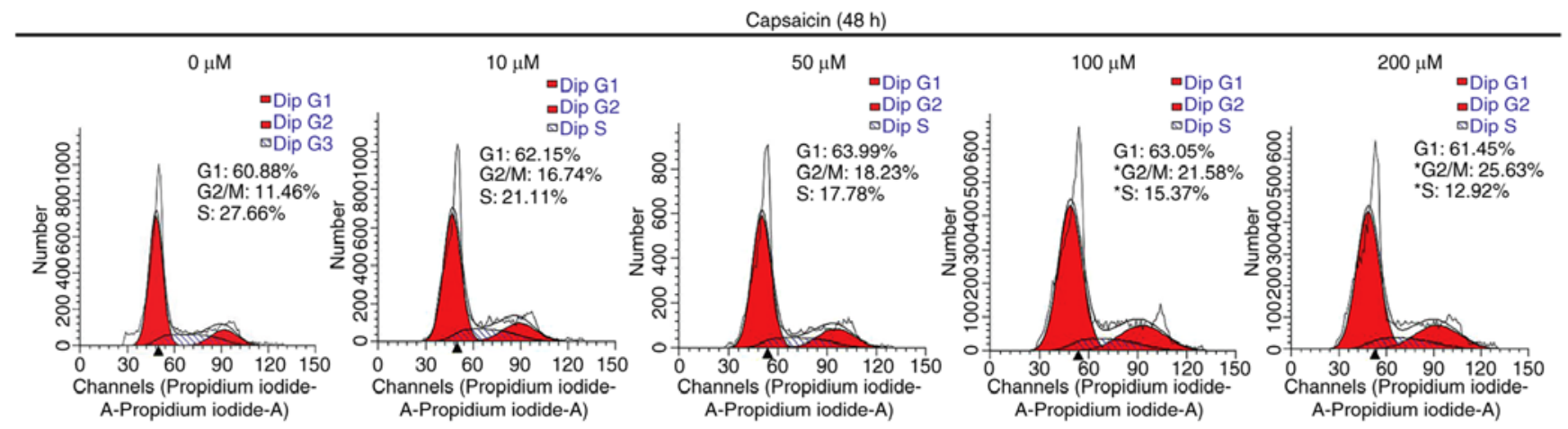

Figure 4. Capsaicin induces $\mathrm{G}_{2} / \mathrm{M}$ cell cycle arrest in MDA-MB-231 breast cancer cells. Cells were seeded $\left(2 \times 10^{5}\right.$ cells $/$ well) into a 6 -well plate at $37^{\circ} \mathrm{C}$ for $24 \mathrm{~h}$. The medium was replaced with serum-free medium and cells were incubated with capsaicin $(10,50,100$ and $200 \mu \mathrm{M})$ for $48 \mathrm{~h}$. The cell cycle distribution was assessed by propidium iodide staining via flow cytometry.

serves an important role in cell proliferation and differentiation $(25,26)$. The aforementioned results indicated that capsaicin inhibited cell viability and migration. Therefore, whether capsaicin inhibited $\mathrm{Wnt} / \beta$-catenin signaling in MDA-MB-231 breast cancer cells was investigated. MDAMB-231 cells were treated with or without capsaicin for $24 \mathrm{~h}$. The results suggested that 50, 100 and $200 \mu \mathrm{M}$ capsaicin significantly decreased the expression levels of Wnt and $\beta$-catenin in MDA-MB-231 cells compared with the control group (Fig. 6A and B). Moreover, pretreatment with the CDK8 inhibitor (Senexin A; $2.5 \mu \mathrm{M}$ ) also significantly decreased the expression levels of Wnt and $\beta$-catenin in vitro compared with the control group (Fig. 6A and B).
Collectively, the results indicated that capsaicin inhibited breast cancer cell migration potentially via suppressing the CDK8/Wnt/ $\beta$-catenin signaling pathway.

\section{Discussion}

The present study demonstrated that CDK8 was significantly upregulated in breast cancer cells compared with healthy breast cells. In addition, the results indicated that, compared with the control group, capsaicin significantly inhibited breast cancer cell viability and migration by suppressing CDK8 expression and the PI3K/Akt/Wnt/ $\beta$-catenin signaling pathway in vitro (Fig. 7). 
A

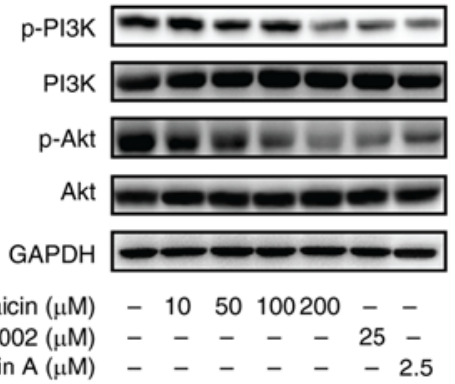

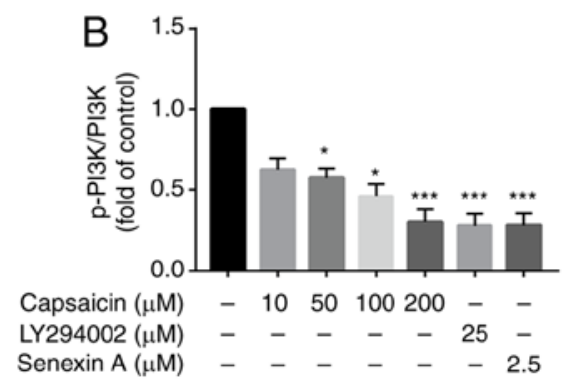

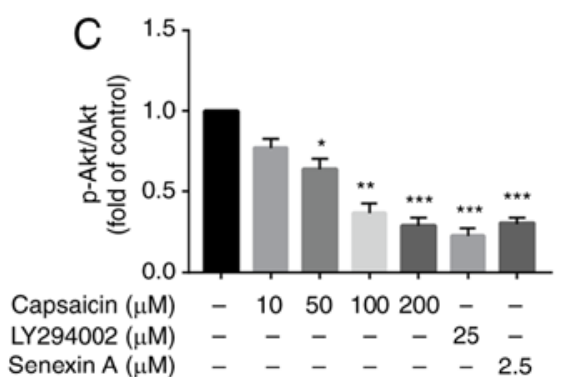

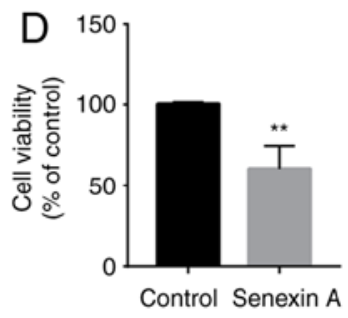
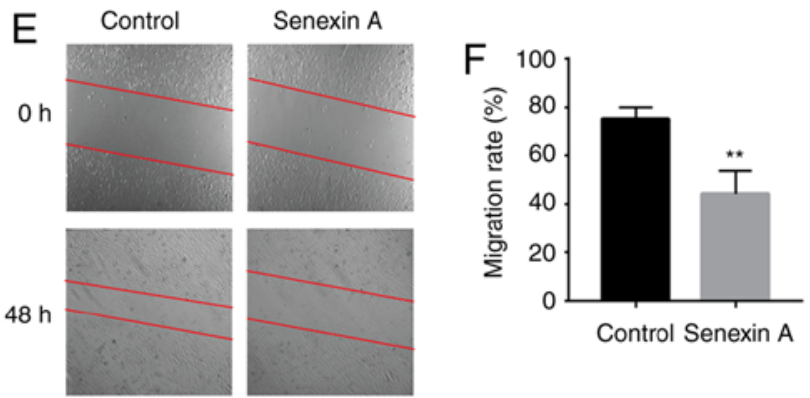

Figure 5. Capsaicin inhibits breast cancer cell viability by downregulating the CDK8/PI3K/Akt signaling pathway. MDA-MB-231 cells were treated with capsaicin (10, 50, 100 and $200 \mu \mathrm{M}$ ), PI3K inhibitor (LY294002; $25 \mu \mathrm{M})$ or CDK8 inhibitor (Senexin A; $2.5 \mu \mathrm{M})$ for $24 \mathrm{~h}$. Protein expression levels were (A) determined via western blotting, and (B) p-PI3K/PI3K and (C) p-Akt/Akt were semi-quantified. (D) Effect of Senexin on cell viability, as determined by MTT assay. The effect of Senexin on cell migration was (E) assessed by performing a wound healing assay (magnification, $\mathrm{x} 400)$ and (F) the rate of migration was quantified. ${ }^{*} \mathrm{P}<0.05,{ }^{* *} \mathrm{P}<0.01$ and ${ }^{* * *} \mathrm{P}<0.001$ vs. control (one-way ANOVA). CDK8, cyclin-dependent kinase 8; p, phosphorylated.

A

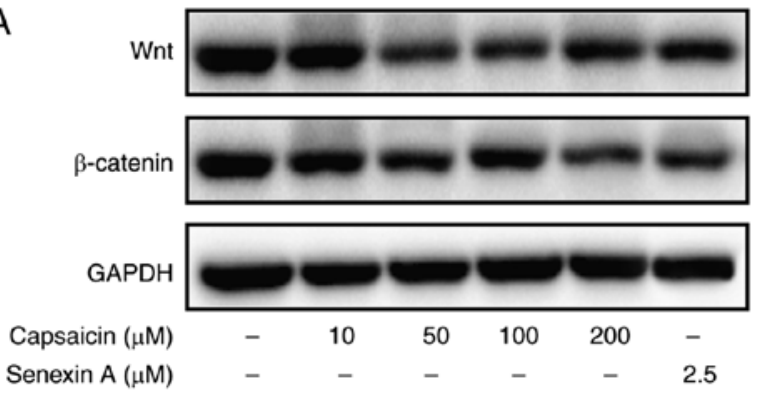

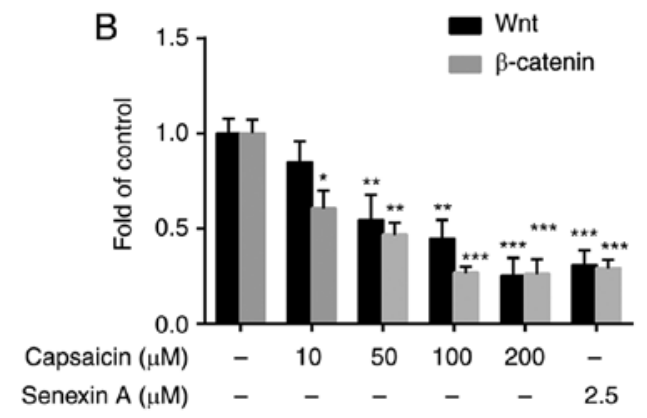

Figure 6. Capsaicin significantly inhibits the Wnt/3-catenin signaling pathway in MDA-MB-231 breast cancer cells. MDA-MB-231 cells were treated with or without capsaicin $(10,50,100$ and $200 \mu \mathrm{M}$ ) and cyclin-dependent kinase 8 inhibitor (Senexin A; $2.5 \mu \mathrm{M}$ ) for $24 \mathrm{~h}$. Wnt and $\beta$-catenin protein expression levels were (A) determined via western blotting and (B) semi-quantified. ${ }^{*} \mathrm{P}<0.05,{ }^{* *} \mathrm{P}<0.01$ and ${ }^{* * *} \mathrm{P}<0.001$ vs. control (one-way ANOVA).

CDKs are cell cycle regulator kinases, which can interact with cyclins and alter CDK inhibitor-mediated cell cycling. Under stable conditions, CDKs primarily regulate the cell cycle at two restriction points, $G_{0} / G_{1}$ and $G_{2} / M$ phases. However, abnormal CDK expression leads to loss of control of the two regulatory points, resulting in proliferating cells continuously entering the cell cycle, thereby disturbing proliferation, differentiation and apoptosis, and leading to the occurrence of malignant tumors (5). CDK8 is a member of the CDK family that promotes cell cycle phase transition, initiates DNA synthesis and regulates cellular transcription. Moreover, CDK8 also serves an important role in regulating the cell cycle and cell proliferation at the transcriptional level (27). Cai et al (28) demonstrated that CDK8 is a key factor in the development of cervical cancer, and the expression of CDK8 was gradually increased with the severity of the lesion. In addition, CDK8 has been reported to affect the occurrence and development of colorectal cancer metastasis and malignant melanoma (29). In colorectal cancer, the $\beta$-catenin signaling pathway is usually activated, and CDK8, as the upstream signaling molecule of $\beta$-catenin, promotes not only its accumulation in the cytoplasm, but also its nuclear transfer (12). Moreover, Kapoor et al (30) reported that CDK8 knockout significantly inhibited the proliferation and metastasis of malignant melanoma cells. In the present study, the mRNA and protein expression levels of CDK8 were significantly increased in MDA-MB-231 breast cancer cells compared with MCF10A healthy breast cells. Furthermore, CDK8 knockdown significantly inhibited breast cancer cell viability and migration compared with the LV-NC-shRNA group. Based on the results of the aforementioned studies and the present study, it was hypothesized that CDK8 may serve as a therapeutic target for breast cancer, and suppressing CDK8 may inhibit breast cancer cell proliferation and metastasis.

Capsaicin, a natural compound, displays various pharmacological properties, including antibacterial, analgesic and 


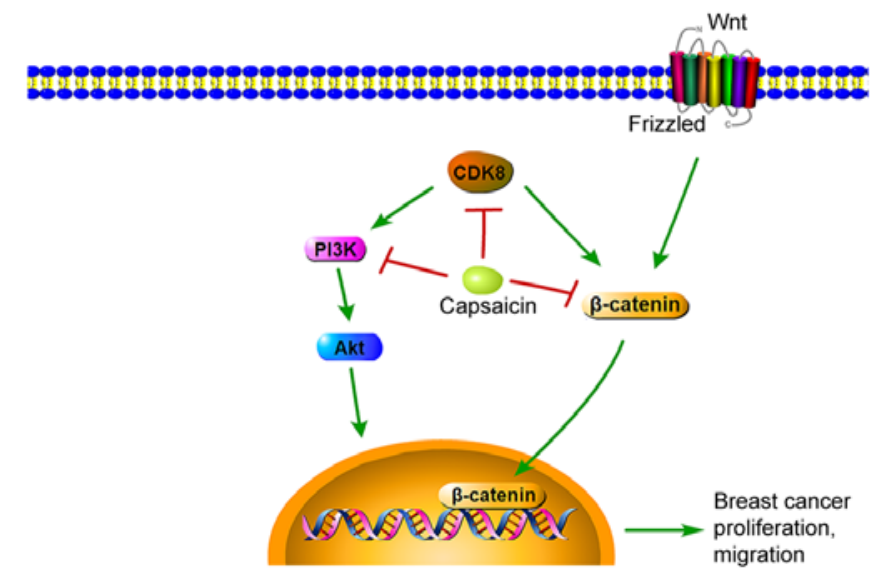

Figure 7. Capsaicin significantly inhibits CDK8 aberrant upregulation and induces $\mathrm{G}_{2} / \mathrm{M}$ cell cycle arrest in MDA-MB-231 breast cancer cells. Moreover, capsaicin can suppress breast cancer cell proliferation and migration, and the underlying mechanism may involve inhibition of the PI3K/Akt/Wnt/B-catenin signaling pathway. $\mathrm{CDK} 8$, cyclin-dependent kinase 8 .

antitumor effects (31). Clinically, capsaicin has been used as an analgesic in topical ointments and dermal patches to relieve pain, typically at concentrations of $0.025-0.1 \%$ (32). High-concentration capsaicin patches (Qutenza) have been approved by the Food and Drug Administration for the treatment of post-herpetic neuralgia, HIV-neuropathy and diabetic neuropathy (33). In recent years, the antitumor activity of capsaicin has been investigated, and increasing evidence has demonstrated that capsaicin could inhibit NF- $\mathrm{kB}$ and Akt/mTOR signaling pathways in pancreatic and colon cancer $(34,35)$. Moreover, previous studies have indicated that capsaicin could induce breast cancer cell apoptosis via mitochondrial dysfunction (36). An analogue of capsaicin, MRS1477, a positive allosteric modulator of transient receptor potential cation channel subfamily $\mathrm{V}$ member 1 , has been shown to reduce MCF7 breast cancer cell viability (37). To further explore the mechanisms underlying capsaicin in breast cancer, MDA-MB-231 cells were selected in the present study. The results indicated that, compared with the control group, capsaicin significantly inhibited MDA-MB-231 cell viability and migration by inducing $\mathrm{G}_{2} / \mathrm{M}$ cell cycle arrest, which may serve as one of the key mechanisms underlying inhibition of breast cancer cell proliferation. Although previous studies have reported that capsaicin can induce cell cycle arrest at the $\mathrm{G}_{0} / \mathrm{G}_{1}$ phase (38), other studies have indicated that capsaicin and its analogs induce cell cycle arrest at the $\mathrm{G}_{2} / \mathrm{M}$ phase $(39,40)$. The inconsistencies between the studies may be due to varied tumor cell types or inconsistent detection timing.

Breast cancer is a complex disease caused by a variety of factors that activate multiple signaling pathways, including the PI3K/Akt/mTOR, RAF/MEK/ERK and endoplasmic reticulum (ER) stress signaling pathways (41-43). PI3K is the main intracellular factor in the transmission of cell migration signals (44). In addition, Akt, one of the major downstream targets of PI3K, promotes cancer cell motility and migration in the tumor microenvironment (45). It has also been reported that targeting the PI3K/Akt/mTOR signaling pathway is promising for the treatment of breast cancer (46). In the present study, capsaicin decreased the expression levels of p-PI3K and p-Akt in MDA-MB-231 cells compared with the control group. Pretreatment with LY294002 or a CDK8 inhibitor also significantly decreased the expression levels of p-PI3K and p-Akt in vitro. Collectively, these results indicated that capsaicin-mediated inhibition of breast cancer cell viability was associated with suppression of the CDK8/PI3K/Akt signaling pathway.

Wnt signaling is an important signaling pathway involved in the regulation of cell proliferation, differentiation and morphogenesis in different organs (47). $\beta$-catenin, an important signaling molecule of the Wnt/ $\beta$-catenin signaling pathway, moves freely within cells, contributes to cell-cell adhesions in the membrane and functions as a transcriptional activator in the nucleus (12). When the Wnt signal is activated, $\beta$-catenin can be translocated into the nucleus and participate in normal development or tumorigenesis by regulating multiple cellular functions (26). It has previously been demonstrated that CDK8 may act as a positive regulator of $\mathrm{Wnt} / \beta$ catenin signaling, which can be increased in several types of human cancer, such as lung, prostate, breast, liver and colon cancer (48). Moreover, it has been reported that CDK8 can not only directly induce the activation of $\beta$-catenin-mediated transcription targets (49), but also indirectly activate $\beta$-catenin-dependent transcription targets by inhibiting E2F transcription factor 1 (50). In the present study, compared with the control group, capsaicin significantly reduced the expression levels of $\beta$-catenin in MDA-MB-231 cells, and pretreatment with CDK8 inhibitor also markedly decreased the expression of $\beta$-catenin in breast cancer cells.

The present study indicated that capsaicin induced $\mathrm{G}_{2} / \mathrm{M}$ cell cycle arrest and inhibited breast cancer cell viability compared with the control group. In addition, compared with the control group, capsaicin decreased the expression of $\mathrm{CDK} 8$, and reduced breast cancer cell viability and migration by inhibiting the PI3K/Akt/Wnt/ $\beta$-catenin signaling pathway. In summary, the results of the present study identified a role for capsaicin in inhibiting breast cancer cell viability by suppressing the CDK8/PI3K/Akt/Wnt/ $\beta$-catenin signaling pathway.

\section{Acknowledgements}

Not applicable.

\section{Funding}

No funding was received.

\section{Availability of data and materials}

The datasets used and/or analyzed during the current study are available from the corresponding author on reasonable request.

\section{Authors' contributions}

DW and HJ designed the study and performed the experiments. DW, HJ and ZZ collected and analyzed the data. SL conceptualized the study, drafted the work and revised it critically for important intellectual content. All authors read and approved the final manuscript. 


\section{Ethics approval and consent to participate}

Not applicable.

\section{Patient consent for publication}

Not applicable.

\section{Competing interests}

The authors declare that they have no competing interests.

\section{References}

1. Bray F, Ferlay J, Soerjomataram I, Siegel RL, Torre LA and Jemal A: Global cancer statistics 2018: GLOBOCAN estimates of incidence and mortality worldwide for 36 cancers in 185 countries. CA Cancer J Clin 68: 394-424, 2018.

2. Burney IA, Furrukh M and Al-Moundhri MS: What are our options in the fight against breast cancer? Sultan Qaboos Univ Med J 14: e149-e151, 2014.

3. Akarolo-Anthony SN, Ogundiran TO and Adebamowo CA: Emerging breast cancer epidemic: Evidence from Africa. Breast Cancer Res 12 (Suppl 4): S8, 2010.

4. Pan H, Gray R, Braybrooke J, Davies C, Taylor C, McGale P, Peto R, Pritchard KI, Bergh J, Dowsett M, et al: 20-Year risks of breast-cancer recurrence after stopping endocrine therapy at 5 years. N Engl J Med 377: 1836-1846, 2017.

5. Roskoski R Jr: Cyclin-dependent protein serine/threonine kinase inhibitors as anticancer drugs. Pharmacol Res 139: 471-488, 2019.

6. Asghar U, Witkiewicz AK, Turner NC and Knudsen ES: The history and future of targeting cyclin-dependent kinases in cancer therapy. Nat Rev Drug Discov 14: 130-146, 2015.

7. Leake R: The cell cycle and regulation of cancer cell growth. Ann N Y Acad Sci 784: 252-262, 1996.

8. Sarita Rajender P, Ramasree D, Bhargavi K, Vasavi M and Uma V: Selective inhibition of proteins regulating CDK/cyclin complexes: Strategy against cancer-a review. J Recept Signal Transduct Res 30: 206-213, 2010.

9. Rzymski T, Mikula M, Wiklik K and Brzozka K: CDK8 kinase-an emerging target in targeted cancer therapy. Biochim Biophys Acta 1854: 1617-1629, 2015.

10. Xi M, Chen T, Wu C, Gao X, Wu Y, Luo X, Du K, Yu L, Cai T, Shen R and Sun H: CDK8 as a therapeutic target for cancers and recent developments in discovery of CDK8 inhibitors. Eur J Med Chem 164: 77-91, 2019.

11. Pelish HE, Liau BB, Nitulescu II, Tangpeerachaikul A, Poss ZC, Da Silva DH, Caruso BT, Arefolov A, Fadeyi O, Christie AL, et al: Mediator kinase inhibition further activates super-enhancer-associated genes in AML. Nature 526: 273-276, 2015.

12. Firestein R, Bass AJ, Kim SY, Dunn IF, Silver SJ, Guney I, Freed E, Ligon AH, Vena N, Ogino S, et al: CDK8 is a colorecta cancer oncogene that regulates beta-catenin activity. Nature 455 547-551, 2008.

13. Donner AJ, Ebmeier CC, Taatjes DJ and Espinosa JM: CDK8 is a positive regulator of transcriptional elongation within the serum response network. Nat Struct Mol Biol 17: 194-201, 2010.

14. Trakala $M$ and Malumbres M: Cyclin C surprises in tumour suppression. Nat Cell Biol 16: 1031-1033, 2014.

15. Philip S, Kumarasiri M, Teo T, Yu M and Wang $S$ : Cyclin-dependent kinase 8: A new hope in targeted cancer therapy? J Med Chem 61: 5073-5092, 2018.

16. McDermott MS, Chumanevich AA, Lim CU, Liang J, Chen M, Altilia S, Oliver D, Rae JM, Shtutman M, Kiaris H, et al: Inhibition of CDK8 mediator kinase suppresses estrogen dependent transcription and the growth of estrogen receptor positive breast cancer. Oncotarget 8: 12558-12575, 2017.

17. Zhu M, Yu X, Zheng Z, Huang J, Yang X and Shi H: Capsaicin suppressed activity of prostate cancer stem cells by inhibition of Wnt/ $\beta$-catenin pathway. Phytother Res 34: 817-824, 2020.

18. Rollyson WD, Stover CA, Brown KC, Perry HE, Stevenson CD, McNees CA, Ball JG, Valentovic MA and Dasgupta P: Bioavailability of capsaicin and its implications for drug delivery. J Control Release 196: 96-105, 2014
19. Linderoth L, Peters GH, Madsen R and Andresen TL: Drug delivery by an enzyme-mediated cyclization of a lipid prodrug with unique bilayer-formation properties. Angew Chem Int Ed Engl 48: 1823-1826, 2009

20. Shin DH, Kim OH, Jun HS and Kang MK: Inhibitory effect of capsaicin on B16-F10 melanoma cell migration via the phosphatidylinositol 3-kinase/Akt/Racl signal pathway. Exp Mol Med 40: 486-494, 2008

21. Livak KJ and Schmittgen TD: Analysis of relative gene expression data using real-time quantitative PCR and the 2(-Delta Delta C(T)) method. Methods 25: 402-408, 2001.

22. Menzl I, Witalisz-Siepracka A and Sexl V: CDK8-Novel therapeutic opportunities. Pharmaceuticals (Basel) 12: 92, 2019.

23. He L, Lu N, Dai Q, Zhao Y, Zhao L, Wang H, Li Z, You Q and Guo Q: Wogonin induced G1 cell cycle arrest by regulating Wnt/ $\beta$-catenin signaling pathway and inactivating CDK8 in human colorectal cancer carcinoma cells. Toxicology 312: 36-47, 2013.

24. Xu D, Li CF, Zhang X, Gong Z, Chan CH, Lee SW, Jin G, Rezaeian AH, Han F, Wang J, et al: Skp2-macroH2A1-CDK8 axis orchestrates $\mathrm{G} 2 / \mathrm{M}$ transition and tumorigenesis. Nat Commun 6: 6641, 2015.

25. Li K, Pan WT, Ma YB, Xu XL, Gao Y, He YQ, Wei L and Zhang JW: BMX activates Wnt/ $\beta$-catenin signaling pathway to promote cell proliferation and migration in breast cancer. Breast Cancer 27: 363-371, 2020

26. Katoh $\mathrm{M}$ and Katoh M: WNT signaling pathway and stem cell signaling network. Clin Cancer Res 13: 4042-4045, 2007.

27. Galbraith MD, Donner AJ and Espinosa JM: CDK8: A positive regulator of transcription. Transcription 1: 4-12, 2010.

28. Cai WS, Shen F, Feng Z, Chen JW, Liu QC, Li EM, Xu B and Cao J: Downregulation of CDK-8 inhibits colon cancer hepatic metastasis by regulating Wnt/ $\beta$-catenin pathway. Biomed Pharmacother 74: 153-157, 2015

29. $\mathrm{Xu} \mathrm{W}$ and Ji JY: Dysregulation of CDK8 and cyclin C in tumorigenesis. J Genet Genomics 38: 439-452, 2011

30. Kapoor A, Goldberg MS, Cumberland LK, Ratnakumar K, Segura MF, Emanuel PO, Menendez S, Vardabasso C, Leroy G, Vidal CI, et al: The histone variant macroH2A suppresses melanoma progression through regulation of CDK8. Nature 468: 1105-1109, 2010.

31. Aggarwal BB, Kunnumakkara AB, Harikumar KB, Tharakan ST, Sung B and Anand P: Potential of spice-derived phytochemicals for cancer prevention. Planta Med 74: 1560-1569, 2008.

32. Fattori V, Hohmann MS, Rossaneis AC, Pinho-Ribeiro FA and Verri WA: Capsaicin: Current understanding of its mechanisms and therapy of pain and other pre-clinical and clinical uses. Molecules 21: 844, 2016.

33. Sharma SK, Vij AS and Sharma M: Mechanisms and clinical uses of capsaicin. Eur J Pharmacol 720: 55-62, 2013.

34. Bessler $\mathrm{H}$ and Djaldetti M: Capsaicin modulates the immune cross talk between human mononuclears and cells from two colon carcinoma lines. Nutr Cancer 69: 14-20, 2017.

35. Zhang JH, Lai FJ, Chen H, Luo J, Zhang RY, Bu HQ, Wang ZH, Lin $\mathrm{HH}$ and Lin SZ: Involvement of the phosphoinositide 3-kinase/Akt pathway in apoptosis induced by capsaicin in the human pancreatic cancer cell line PANC-1. Oncol Lett 5: 43-48, 2013.

36. Chang HC, Chen ST, Chien SY, Kuo SJ, Tsai HT and Chen DR: Capsaicin may induce breast cancer cell death through apoptosis-inducing factor involving mitochondrial dysfunction. Hum Exp Toxicol 30: 1657-1665, 2011.

37. Nazıroğlu M, Cĭ̆ B, Blum W, Vizler C, Buhala A, Marton A, Katona R, Jósvay K, Schwaller B, Oláh Z and Pecze L: Targeting breast cancer cells by MRS1477, a positive allosteric modulator of TRPV1 channels. PLoS One 12: e0179950, 2017.

38. Qian K, Wang G, Cao R, Liu T, Qian G, Guan X, Guo Z, Xiao Y and Wang X: Capsaicin suppresses cell proliferation, induces cell cycle arrest and ROS production in bladder cancer cells through FOXO3a-mediated pathways. Molecules 21: 1406, 2016.

39. Lin $\mathrm{CH}$, Lu WC, Wang CW, Chan YC and Chen MK: Capsaicin induces cell cycle arrest and apoptosis in human KB cancer cells. BMC Complement Altern Med 13: 46, 2013.

40. de-Sá-Júnior PL, Pasqualoto KFM, Ferreira AK, Tavares MT, Costa Bernstorff Damião MCF, de Azevedo RA, Dias Câmara DA, Pereira A, de Souza DM and Filho RP: RPF101, a new capsaicin-like analogue, disrupts the microtubule network accompanied by arrest in the $\mathrm{G} 2 / \mathrm{M}$ phase, inducing apoptosis and mitotic catastrophe in the MCF-7 breast cancer cells. Toxicol Appl Pharmacol 266: 385-398, 2013. 
41. Sharma VR, Gupta GK, Sharma AK, Batra N, Sharma DK, Joshi A and Sharma AK: PI3K/Akt/mTOR intracellular pathway and breast cancer: Factors, mechanism and regulation. Curr Pharm Des 23: 1633-1638, 2017.

42. Saini KS, Loi S, de Azambuja E, Metzger-Filho O, Saini ML, Ignatiadis M, Dancey JE and Piccart-Gebhart MJ: Targeting the $\mathrm{PI} 3 \mathrm{~K} / \mathrm{AKT} / \mathrm{mTOR}$ and Raf/MEK/ERK pathways in the treatment of breast cancer. Cancer Treat Rev 39: 935-946, 2013.

43. Nougarede A, Popgeorgiev N, Kassem L, Omarjee S, Borel S, Mikaelian I, Lopez J, Gadet R, Marcillat O, Treilleux I, et al: Breast cancer targeting through inhibition of the endoplasmic reticulum-based apoptosis regulator $\mathrm{Nrh} / \mathrm{BCL} 2 \mathrm{~L} 10$. Cancer Res 78: 1404-1417, 2018.

44. Shi L, Wu Z, Miao J, Du S, Ai S, Xu E, Feng M, Song J and Guan W: Adenosine interaction with adenosine receptor A 2 a promotes gastric cancer metastasis by enhancing PI3K-AKT-mTOR signaling. Mol Biol Cell 30: 2527-2534, 2019.

45. Ghosh JC, Seo JH, Agarwal E, Wang Y, Kossenkov AV, Tang HY, Speicher DW and Altieri DC: Akt phosphorylation of mitochondrial Lonp1 protease enables oxidative metabolism and advanced tumor traits. Oncogene 38: 6926-6939, 2019.

46. Guo $\mathrm{Y}$ and Pei X: Tetrandrine-induced autophagy in MDA-MB-231 triple-negative breast cancer cell through the inhibition of PI3K/AKT/mTOR signaling. Evid Based Complement Alternat Med 2019: 7517431, 2019.
47. Kleszcz R: The canonical Wnt pathway. Postepy Biochem 65: 183-192, 2019 (In Polish).

48. Kim MY, Han SI and Lim SC: Roles of cyclin-dependent kinase 8 and $\beta$-catenin in the oncogenesis and progression of gastric adenocarcinoma. Int J Oncol 38: 1375-1383, 2011.

49. Firestein R, Shima K, Nosho K, Irahara N, Baba Y, Bojarski E, Giovannucci EL, Hahn WC, Fuchs CS and Ogino S: CDK8 expression in 470 colorectal cancers in relation to beta-catenin activation, other molecular alterations and patient survival. Int J Cancer 126: 2863-2873, 2010.

50. Broude EV, Gyorffy B, Chumanevich AA, Chen M, McDermott MSJ, Shtutman M, Catroppo JF and Roninson IB: Expression of CDK8 and CDK8-interacting genes as potential biomarkers in breast cancer. Curr Cancer Drug Targets 15: 739-749, 2015.

This work is licensed under a Creative Commons Attribution-NonCommercial-NoDerivatives 4.0 International (CC BY-NC-ND 4.0) License. 